\title{
BMJ Open Dimensions of safety culture: a systematic review of quantitative, qualitative and mixed methods for assessing safety culture in hospitals
}

\author{
Kate Churruca (D) , ${ }^{1}$ Louise A Ellis (D) , ${ }^{1}$ Chiara Pomare (D) , ${ }^{1}$ Anne Hogden (D) , ${ }^{1,2}$ \\ Mia Bierbaum (D) , Janet C Long (D) , ${ }^{1}$ Aleksandra Olekalns, ${ }^{1}$ \\ Jeffrey Braithwaite (1) ${ }^{1}$
}

To cite: Churruca K, Ellis LA, Pomare C, et al. Dimensions of safety culture: a systematic review of quantitative, qualitative and mixed methods for assessing safety culture in hospitals. BMJ Open 2021;11:e043982. doi:10.1136/ bmjopen-2020-043982

- Prepublication history and supplemental material for this paper is available online. To view these files, please visit the journal online (http://dx.doi. org/10.1136/bmjopen-2020043982).

Received 11 January 2021 Accepted 01 July 2021

D Check for updates

(c) Author(s) (or their employer(s)) 2021. Re-use permitted under CC BY-NC. No commercial re-use. See rights and permissions. Published by BMJ.

${ }^{1}$ Australian Institute of Health Innovation, Macquarie University, Sydney, New South Wales, Australia

${ }^{2}$ Australian Institute of Health Service Management, University of Tasmania, Hobart, Tasmania, Australia

Correspondence to

Dr Kate Churruca;

kate.churruca@mq.edu.au

\section{ABSTRACT}

Background The study of safety culture and its relationship to patient care have been challenged by variation in definition, dimensionality and methods of assessment. This systematic review aimed to map methods to assess safety culture in hospitals, analyse the prevalence of these methods in the published research literature and examine the dimensions of safety culture captured through these processes.

Methods We included studies reporting on quantitative, qualitative and mixed methods to assess safety culture in hospitals. The review was conducted using four academic databases (PubMed, CINAHL, Scopus and Web of Science) with studies from January 2008 to May 2020. A formal quality appraisal was not conducted. Study purpose, type of method and safety culture dimensions were extracted from all studies, coded thematically, and summarised narratively and using descriptive statistics where appropriate.

Results A total of 694 studies were included. A third $(\mathrm{n}=244,35.2 \%)$ had a descriptive or exploratory purpose, $225(32.4 \%)$ tested relationships among variables, 129 (18.6\%) evaluated an intervention, while $13.8 \%(n=96)$ had a methodological focus. Most studies exclusively used surveys $(\mathrm{n}=663 ; 95.5 \%)$, with 88 different surveys identified. Only 31 studies (4.5\%) used qualitative or mixed methods. Thematic analysis identified 11 themes related to safety culture dimensions across the methods, with 'Leadership' being the most common. Qualitative and mixed methods approaches were more likely to identify additional dimensions of safety culture not covered by the 11 themes, including improvisation and contextual pressures.

Discussion We assessed the extent to which safety culture dimensions mapped to specific quantitative and qualitative tools and methods of assessing safety culture. No single method or tool appeared to measure all 11 themes of safety culture. Risk of publication bias was high in this review. Future attempts to assess safety culture in hospitals should consider incorporating qualitative methods into survey studies to evaluate this multi-faceted construct.

\section{BACKGROUND}

Over the last two decades, the notion that hospitals have a 'safety culture' that can be
Strengths and limitations of this study

- Reviewed both qualitative and quantitative methods for assessing safety culture in hospitals.

- Examined the extent diverse methods and different surveys provide coverage of safety culture dimensions.

- The literature search was performed in four academic databases.

- Included only published, peer-reviewed and English language empirical studies; potential insights from grey literature not explored.

- Evaluated qualitative and mixed methods separately from quantitative surveys.

measured, understood and improved, has become a pillar of the patient safety movement, ${ }^{1}$ and is increasingly embodied in accreditation and regulatory standards. ${ }^{2}{ }^{3}$ Accordingly, the need for robust assessment of safety culture has become evident, ${ }^{4}$ and tools have proliferated. ${ }^{56}$ Nowadays, safety culture assessment is widely used in hospitals for four key reasons, namely, to: (1) diagnose safety culture and identify areas for improvement; (2) evaluate patient safety interventions or programmes and track change over time; (3) conduct internal and external benchmarking; and (4) fulfil directives or regulatory requirements. ${ }^{17}$ Despite expanding interest in studying and addressing safety culture over the last decade and a half, several challenges persist in defining and assessing the dimensions of safety culture.

\section{Defining safety culture}

There are many definitions of safety culture, both within and outside of healthcare. Cooper $^{8}$ evocatively summarised the situation well in his description of the field as a 'definitional swamp', highlighting 51 separate 
definitions of safety culture and 30 separate definitions of safety climate. Compounding equivocality, many researchers mark a distinction between safety climate and safety culture, ${ }^{7}$ suggesting the former involves peoples' perceptions of their organisations (its procedures, practices and the kinds of behaviour that are tolerated or rewarded), whereas culture operates on a deeper, more enduring level, representing the behaviours, practices and the underlying, sometimes unconscious, beliefs and values within an organisation. ${ }^{9}$ Others in the field use culture and climate interchangeably. ${ }^{10}$

A typical definition of safety culture is: ${ }^{11}$ 'The product of individual and group values, attitudes, perceptions, competencies and patterns of behaviour that determine the commitment to, and the style and proficiency of, an organization's health and safety management' ( $p$. 339). ${ }^{12}$ Although this provides some guidance on which constructs to consider when assessing safety culture, the specificities of the attitudes, values and norms conducive to safety, as well as how to assess them, is less clear.

\section{Assessment of safety culture and its dimensions}

Safety culture is considered multifaceted, consisting of several inter-related attributes or dimensions, although consensus on these dimensions remains elusive. ${ }^{12}{ }^{13}$ For example, while some conceptualise safety culture as exclusively the prioritisation of safety by the unit and organisational leadership, ${ }^{14}$ others construe it more broadly to include learning, reporting and blame orientation. ${ }^{15-17}$ Recognising and responding to this equivocality, over the years several reviews of safety culture assessment in healthcare have examined dimensions, highlighting the most frequent. ${ }^{9121819}$ While the themes these reviews have delineated overlap, they differ considerably in scope (ie, some are broad, while others are specific) and quantity. These similarities and differences are summarised in table 1, where thematically-related dimensions are presented on the same row.

Only one of these reviews included qualitative and mixed method approaches alongside quantitative surveys. ${ }^{12} \mathrm{~A}$ decade ago, Halligan and Zecevic found only 14 of 137 articles used qualitative methods (eg, interviews, focus groups); given the preponderance of quantitative surveys, limited discussion was given to these methods and it was not clear how they mapped to the dimensions of safety culture they identified or whether these studies uncovered additional insights into safety culture in hospitals.

The widespread, exclusive use of surveys to assess safety culture differentiates healthcare from other industries where a range of methods are typically used together. ${ }^{20-22}$ This is because surveys alone do not expose rich insights into dimensions of culture. ${ }^{23}$ Following Schein's model of organisational culture ${ }^{24}$ which has been widely adopted in healthcare,${ }^{25}$ and to understand safety culture, ${ }^{1326}$ surveys capture the first two layers of artefacts and espoused beliefs rather than the deeper underlying shared assumptions at the heart of an organisation's culture. Cultural dimensions are also arguably to some extent contextually dependent, cannot be pre-specified and hence require rich interpretive methods to uncover: 'every organization has a unique profile of cultural assumptions that any questionnaire inevitably misses' (p. 615) ${ }^{27}$ In-depth, open-ended, qualitative methods are considered better suited to accessing these deeper facets and contextual nuances of culture, ${ }^{24}{ }^{28}$ because their iterative, interactive nature allows for questions and therefore the conceptualisation of safety culture, to evolve in response to feedback as data are collected. ${ }^{29}$

\section{The present review}

There has been limited integration of qualitative research in past reviews of safety culture assessment in healthcare, with none examining dimensions by type of method. The potential for qualitative methods to uncover additional insights into safety culture dimensions has not been considered. ${ }^{12}$ We set out to map the range of methods and tools used to assess safety culture in hospitals, including qualitative, quantitative and mixed approaches. We sought to analyse the prevalence of use of these methods and tools, the purpose for using them and examine the ways safety culture was conceptualised-including its dimensionsthrough the application of methods or tools.

\section{METHOD}

\section{Search strategy and criteria}

This systematic review followed the Preferred Reporting Items for Systematic Reviews and Meta-Analyses (PRISMA) guidelines (see online supplemental appendix 1 for PRISMA checklist). ${ }^{30}$ Four databases were searched: PubMed, CINAHL, Scopus and Web of Science. The search was from 2008 to May 2020, using a search string based on previous reviews: ${ }^{12}$ ('acute care' OR 'hospital') AND ('quality culture' OR 'safety culture' OR 'culture of safety' OR 'safety climate' OR 'safety attitude') AND ('survey' OR 'questionnaire' OR 'tool' OR 'instrument' OR measur* OR assess* OR checklist OR 'check list' OR observ*) AND ('patient safety' OR 'public safety' OR 'workplace safety'). The full search for Scopus is provided in online supplemental appendix 2.

To be eligible for inclusion in the review, studies were required to have: (1) been an empirical study published in a peer-reviewed journal; (2) used a method(s) or tool(s) for the purposes of assessing, studying or measuring safety culture or climate; (3) collected data in hospital(s); and (4) the study was published in English. Review articles were retained for snowballing and context but were otherwise excluded from this review.

\section{Study selection}

Titles and abstracts were divided and independently reviewed by four of the authors (CP, LAE, KC and AO). Fleiss' kappa statistic ${ }^{31}$ was used to evaluate inter-rater agreement of $5 \%$ of the titles/abstracts by two authors (CP and KC). Snowballing was also used to identify 


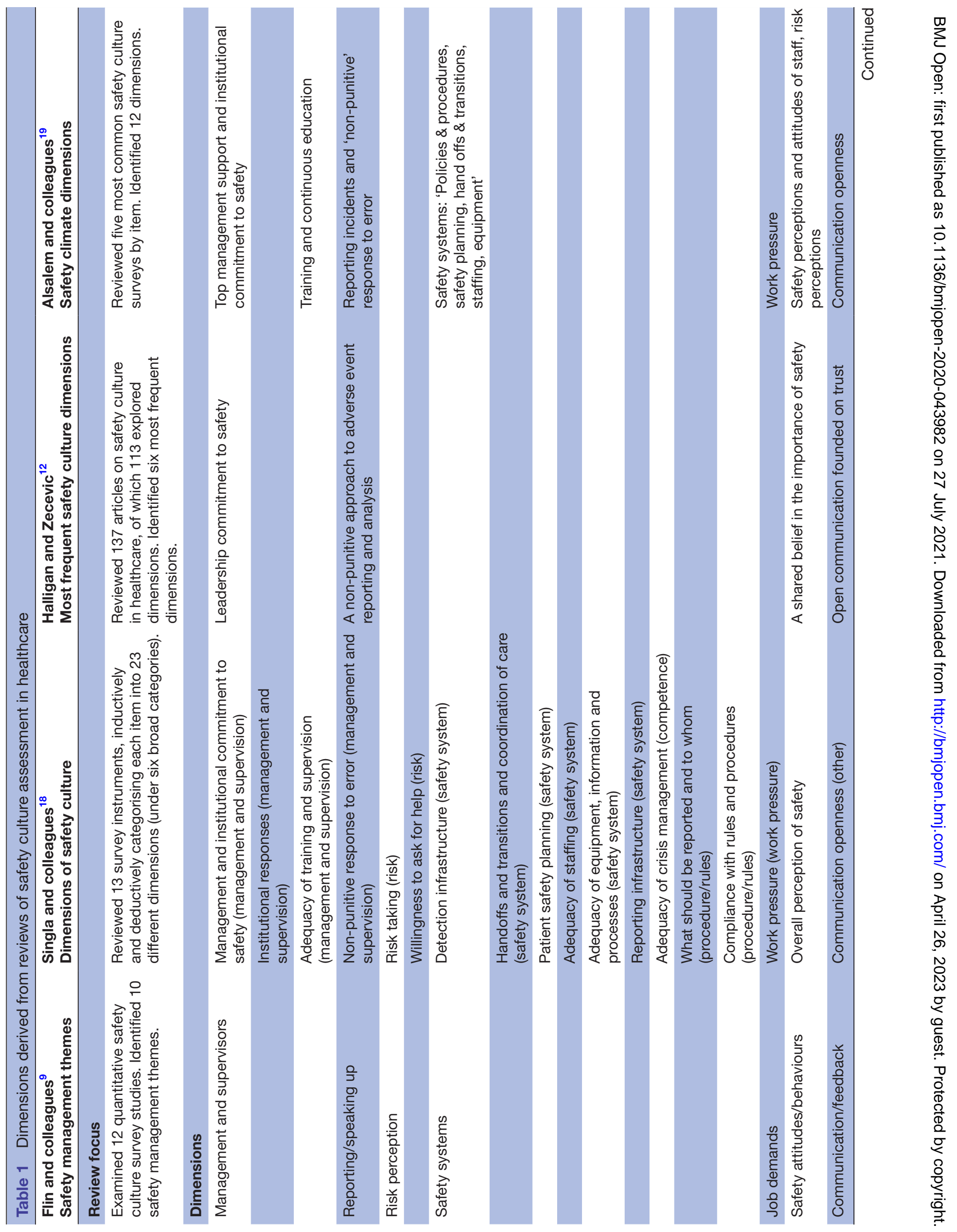




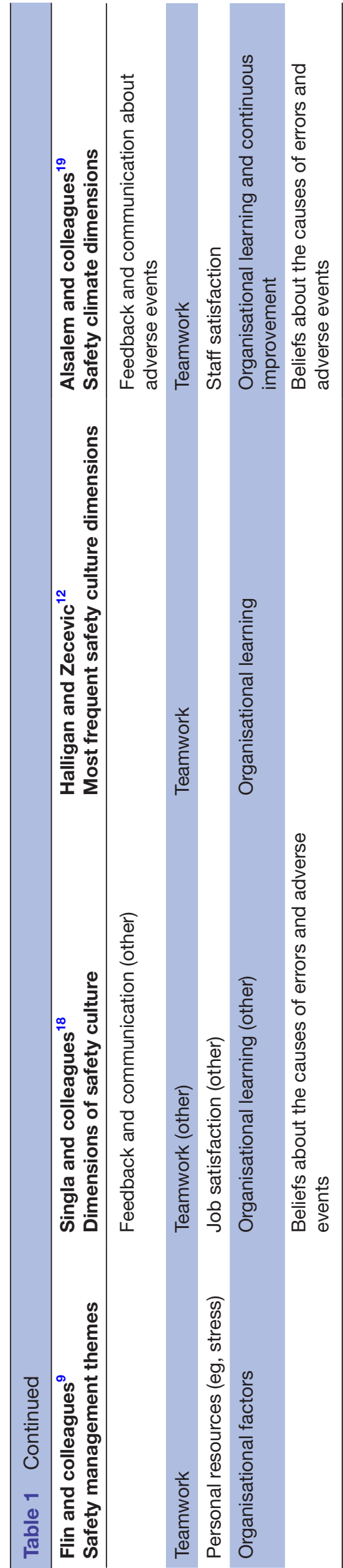

studies from reference lists of included studies and reviews identified.

\section{Examination of methods used to assess safety culture}

The study purpose for all included studies was extracted. The primary study aim was coded into one of four categories to determine whether certain methods were selectively used for certain purposes. These categories, developed collaboratively by the first and second author, were: (1) Descriptive or exploratory assessment of safety culture including comparisons between groups (eg, doctors and nurses, countries) and studies establishing a 'baseline' or identifying areas for improvement; (2) Testing relationships among components of safety culture, or between safety culture and other measured variables; (3) Methodological focus including validation studies or those furthering the assessment of safety culture; or (4) Evaluation of an intervention, typically a programme to improve safety, safety culture or quality. As categories (2) and (3) had a theoretical and methodological focus, respectively, they were deemed purposed for research, whereas categories (1) and (4) were more applied and, therefore, deemed improvement focused.

Other aspects of data extraction differed depending on method. Among the studies exclusively using quantitative surveys, data extraction focused primarily on details of the tool itself rather than the study, including survey origins and details of dimensions and items. For surveys that had been developed by included studies, we noted information on the development of the tool including what, if any, other surveys it had been derived from. For studies that used an already established survey, where required, we found the original source to collect these details.

Due to their bespoke nature, studies that used qualitative or mixed methods to assess safety culture were examined individually. Information on study design (eg, ethnography), methods of data collection (eg, interviews, observations), analysis (eg, thematic analysis) and sometimes results-in the case of iterative data collection and analysis-were inspected to extract information on the method of assessment and the conceptualisation of safety culture. This included review of the types of questions asked during interview (or the interview schedule, if provided), and details of any framework or theory used for analysis.

To extract information on dimensions of safety culture, three of the authors (CP, LAE and $\mathrm{KC}$ ) first deductively developed a draft coding framework by examining dimensions and themes identified in previous reviews. ${ }^{9}{ }^{12} 1819$ As shown in the rows of table 1 , similar dimensions across reviews were organised together, with some refined into broader themes rather than more specific safety categories (eg, safety systems or resources and constraints, rather detection infrastructure, adequacy of staffing). In a workshop session, the framework was then applied to all items $(n=275)$ from eight of the most common surveys. These were coded individually by each author and then responses were discussed together to refine the coding framework 
and its definitions, resolve any disagreement and ensure consistent coding. During this process, the prioritisation of safety and the perceptions of safety (ie, how safe an organisation is) were broken up into distinct themes, because though related, there was sufficient evidence of a distinction and that both were important. After establishing that the coding framework could be applied consistently, the remaining surveys and studies were divided up and coded.

\section{Quality appraisal}

A formal quality assessment was not conducted due to the wide variation in study design, the large number of included studies and the focus of this review being on methods rather than the results of the included studies. However, the information provided in the methods sections and reference lists of included studies was assessed as part of the data extraction process.

\section{Patient and public involvement}

No patients involved.

\section{Ethics statement}

Ethical approval was not required for this systematic review as no human participants were involved.

\section{RESULTS}

The search retrieved a total of 4020 papers, which were downloaded into the reference management software EndNote and duplicates removed, giving 1747 articles. Four studies identified from the reference lists of papers were also reviewed, giving a total of 1751 studies. Following title and abstract screening, 1014 articles were included for full-text review (see figure 1). Of these, 694 articles met inclusion criteria and are included in this review.

The overwhelming majority of included papers $(\mathrm{n}=663$; $95.5 \%$ ) exclusively used self-report quantitative surveys to assess safety culture. A further 19 papers $(2.7 \%)$ were mixed methods studies that reported using surveys in combination with other methods, such as interviews, while 12 papers $(1.7 \%)$ reported solely using qualitative methods. The largest proportion of studies had a descriptive or exploratory purpose $(\mathrm{n}=244,35.2 \%)$, followed closely by testing relationships among variables $(\mathrm{n}=225,32.4 \%)$. Almost one-fifth of studies assessing safety culture evaluated an intervention $(n=129,18.6 \%)$, while $14 \%(n=96)$ had a methodological focus. Purposes differed slightly according to the type of method used

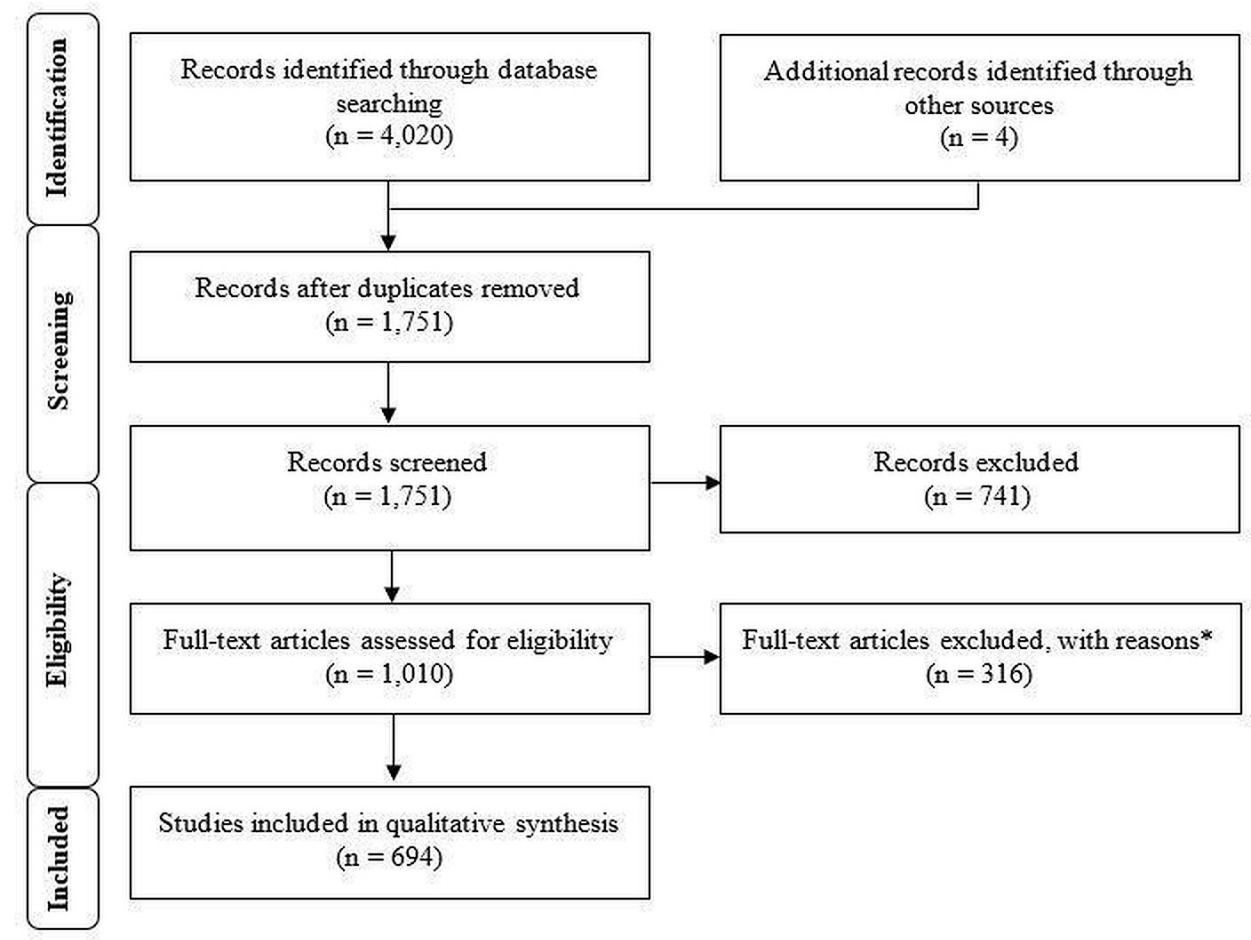

\begin{tabular}{llc}
\hline & \multicolumn{1}{c}{ *Reason for exclusion } & Number of studies \\
\hline $\mathbf{1}$ & Language other than English & 87 \\
\hline $\mathbf{2}$ & Does not assess safety culture & 81 \\
\hline $\mathbf{3}$ & Setting other than acute care/hospitals & 40 \\
\hline $\mathbf{4}$ & Unable to access/find full text & 66 \\
\hline $\mathbf{5}$ & Not an empirical journal article & 53 \\
\hline
\end{tabular}

$\wedge$ The numbers of studies in this column exceeds the total number of exclude studies due to a proportion of studies being excluded for multiple reasons.

Figure 1 Flow chart of the review of literature to identify methods and tools. 


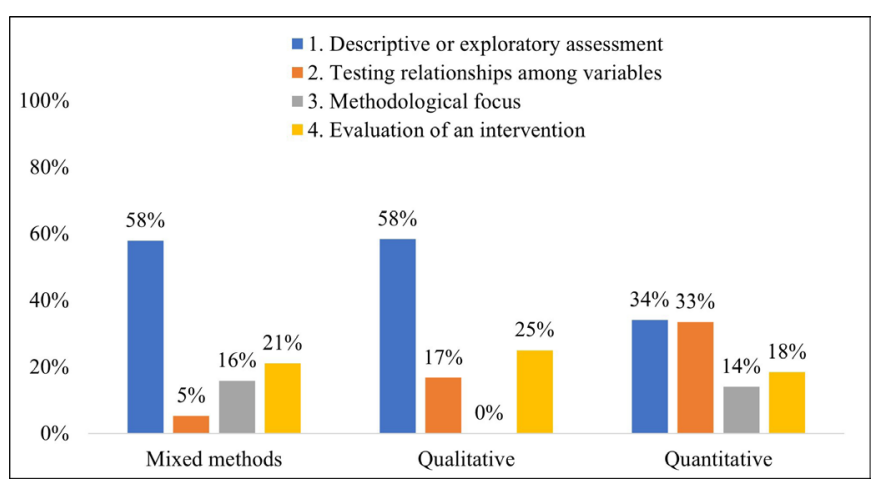

Figure 2 Proportion of included studies for each primary study purpose broken down by method.

(see figure 2), with qualitative and mixed methods studies more likely to be exploratory, and no qualitative studies having an explicit methodological focus. The full list of all included studies is in online supplemental appendix 3 .

\section{Quantitative surveys assessing safety culture}

In total, 88 surveys were identified, 45 of which were new surveys developed by authors of included papers. The most widely-used surveys were the Hospital Survey on Patient Safety Culture (HSOPS; $\mathrm{n}=312 ; 45.7 \%$ ) by the Agency for Healthcare Research and Quality, ${ }^{32}$ and the Safety Attitudes Questionnaire (SAQ; n=209; 30.6\%) developed by Sexton and colleagues at the University of Texas. ${ }^{33}$ This was followed rather distantly by the Patient Safety Climate in Healthcare Organisations (PSCHO), the Safety Climate Survey, the Hospital Safety Climate Scale, the Teamwork and Safety Climate Survey ${ }^{33}$ and the Operating Room Management Attitudes Questionnaire (ORMAQ) ${ }^{35}$ A large proportion $(n=62,70.4 \%)$ of the 88 surveys identified were used only a single time among the 682 survey studies. See table 2 for the most common surveys.

Table 2 Most frequently used surveys to assess safety culture in hospitals.

\begin{tabular}{|c|c|c|}
\hline Name of survey & $\begin{array}{l}\text { Number of } \\
\text { studies }\end{array}$ & $\% *$ \\
\hline $\begin{array}{l}\text { Hospital Survey on Patient Safety } \\
\text { Culture }^{32}\end{array}$ & 312 & 45.7 \\
\hline Safety Attitudes Questionnaire ${ }^{33}$ & 209 & 30.6 \\
\hline $\begin{array}{l}\text { Patient Safety Climate in Healthcare } \\
\text { Organizations }{ }^{6}\end{array}$ & 20 & 2.9 \\
\hline Safety Climate Survey ${ }^{82}$ & 9 & 1.3 \\
\hline Hospital Safety Climate Scale ${ }^{83}$ & 8 & 1.2 \\
\hline $\begin{array}{l}\text { Teamwork and Safety Climate } \\
\text { Survey }^{3334}\end{array}$ & 7 & 1 \\
\hline $\begin{array}{l}\text { Operating Room Management } \\
\text { Attitudes Questionnaire }\end{array}$ & 5 & 0.7 \\
\hline
\end{tabular}

*Proportion of papers using surveys across all studies using surveys $(n=682)$.
The 88 surveys encompassed not only entirely new and unique measures, but also surveys that built on or refined existing tools, or that used some of the same questions. For example, the PSCHO was derived from the Veteran Affairs Palo Alto/Stanford Patient Safety Center of Inquiry (PSCI) survey. ${ }^{6} 36$ The Modified Stanford Instrument and Canadian-Patient Safety Climate Survey—both by Ginsburg and colleagues ${ }^{47}$-are also based on the PSCI but included some questions from the HSOPS.

Of the 45 new measures, many were based at least in part on established measures of safety culture, including the HSOPS and SAQ. Others focused on particular aspects of safety culture within hospitals, such as the Just Culture Assessment Tool $^{38}$ and the Catheter-Related Bloodstream Infection Prevention Practices Survey ${ }^{39}$; or certain staff groups (eg, Junior Doctor-Patient Safety Attitudes and Climate Questionnaire) ${ }^{40}$; were developed for specific settings (eg, maternal and child health institutions, ${ }^{41}$ acute geriatric units ${ }^{42}$ or languages (eg, Chinese) ${ }^{43}$ Distinct from other self-report surveys, the Patients' Perceptions of Safety Culture scale was designed to assess patient, rather than staff, perceptions of hospital safety culture. ${ }^{44}$

\section{Qualitative and mixed methods studies assessing safety culture}

The review identified 31 studies $(4.5 \%)$ that used qualitative or mixed methods to assess safety culture. Interviews were the most common approach $(n=23 ; 74.2 \%)$, followed by frameworks and theories $(\mathrm{n}=11,35.5 \%)$, and focus groups ( $n=9,29 \%)$ (see table 3$)$. Most studies reported their interview schedule or example questions along with the main topics covered. These questions varied in how they were framed and their content (eg, broad and exploratory: 'Can you tell me about what patient safety means to you?' vs more specific and contained: 'How safe do you think is the care provided in the ICU?').

Frameworks or theories were used in 11 studies $(35.5 \%)$ to guide the collection and analysis of qualitative data, and included grounded theory, ${ }^{45}$ a lifeworld versus system distinction, ${ }^{46}$ and the SAQ's dimensions. ${ }^{47} 48$ The

Table 3 Qualitative methods to assess safety culture in hospitals

\begin{tabular}{lll}
\hline & $\begin{array}{l}\text { Number of } \\
\text { studies* }\end{array}$ & \%† \\
\hline Interviews & 23 & 74.2 \\
\hline Framework or theory & 11 & 35.5 \\
\hline Focus groups & 9 & 29 \\
\hline Observations & 5 & 16.1 \\
\hline Document analysis & 5 & 16.1 \\
\hline Ethnography & 2 & 6.5 \\
\hline
\end{tabular}

${ }^{*}$ Frequencies exceed the total number of qualitative/mixed methods studies due to studies using multiple methods/tools. $\dagger \%$ based on total number of qualitative and mixed methods studies $(n=31)$. 
Manchester Patient Safety Framework (MaPSaF) was used across four studies, typically in its conventional facilitated workshop, ${ }^{49-51}$ or as an adapted version..$^{52}$ Similar to surveys, it presupposes a number of dimensions for which staff are required to rate the safety culture in their unit or organisation. However, the response range is not a Likert scale, but classifies cultures along five theorised levels of cultural maturity (ie, pathological, reactive, bureaucratic, proactive, generative).$^{53}$ A quantitative survey tool based on the MaPSaF and using a similar ordinal response range (the Manchester Patient Safety Culture Assessment Tool, MaPSCAT) was also identified by this review. ${ }^{54}$

Observations were used in only five studies (16.1\%), always in conjunction with interviews, focus groups or surveys. One of these studies involved novel nurse led photo elicitation during walkabouts together with focus groups to study the safety culture related to medication management in a Brazilian intensive care unit. ${ }^{55}$ Five studies (16.1\%) analysed organisational documents and data as a window into safety culture. For example, safety checklists used during management walkarounds were analysed and triangulated with survey responses and focus group data in a study of intensive care unit safety culture following a safety intervention. ${ }^{56}$ Finally, two studies $(6.5 \%)$ used a combination of qualitative methods, including observations, informal conversations, interviews, within an ethnographic study design to examine how team communication affected safety culture in surgery, ${ }^{57}$ and the developing patient safety culture of medical residents. ${ }^{46}$

More than half of studies using qualitative methods did so in conjunction with surveys to assess safety culture in a mixed methods design $(n=19,61.3 \%)$, to elaborate ${ }^{4958}$ or compare ${ }^{59}$ with quantitative findings, develop a safety culture survey, ${ }^{60}$ or identify factors influencing patient safety culture. ${ }^{61}$ Some survey studies also incorporated abbreviated qualitative data by including open response questions. ${ }^{5862}$ However, there was insufficient detail on the questions used and any analysis to warrant these studies being classified as mixed methods. An exception was Boussat and colleagues ${ }^{, 63}$ mixed method study, which used open-response comments from a HSOPS survey of a French hospital to develop interview probes and included these answers in the analysis.

\section{Themes for safety culture dimensions}

Details of all 88 surveys and 31 qualitative and mixed methods studies were examined to identify common themes in safety culture dimensions, as well as new or emerging ones. This process led to the identification of 11 themes and an 'other' category. Table 4 displays definitions, example items and how often themes were present in methods/tools reviewed. Information on the proportion of different methods covering each theme is charted in figure 3. Online supplemental appendix 4 shows the mapping of each method or tool to the themes of safety culture identified.
'Leadership' was the most frequently assessed safety culture theme, present in three-quarters of methods and tools reviewed. 'Awareness of human limits' and 'Well-being' were the least frequent across the different methods. All themes were covered to a greater extent by mixed methods studies, compared with using qualitative methods or surveys alone. However, qualitative studies had a relatively higher inclusion of 'other' dimensions.

Although dimensions classified to the 'other' category were too infrequent to constitute their own theme, there were some recurrent concepts. Specifically, across qualitative methods and quantitative surveys, there were dimensions related to patient involvement in safety culture; $;^{416164-66}$ interpersonal dynamics around trusting colleagues, developing a shared understanding and valuing and empowering individuals; ${ }^{3860}$ and the need for flexibility and improvisation. ${ }^{28} 6768$ However, extending on the latter of these themes, qualitative and mixed methods studies also reported a range of complexities, ${ }^{67}$ external pressures ${ }^{69}$ contextual dependencies ${ }^{57}$ and the need to manage and prioritise risks in delivering safe care to patients, ${ }^{45}$ which were not adequately captured by the narrow scope of established themes, such as 'resources and constraints'.

\section{DISCUSSION}

This review sought to: (1) map the range of methods and specific tools used to assess safety culture in hospitals; (2) analyse the prevalence of these in published research; and (3) examine the dimensions of safety culture captured in these methods and tools. We found that the overwhelming majority of studies exclusively used surveys. Few used surveys in combination with other methods or solely qualitative methods. These studies had one of four primary purposes, with quantitative studies more likely to test relationships among variables, and qualitative and mixed methods studies typically more focused on describing and exploring safety culture or evaluating some intervention. We identified 11 safety culture themes and one residual category to cover the range of safety culture dimensions in methods and tools.

\section{Safety culture surveys}

The most widely-used surveys were the HSOPS, ${ }^{32}$ and the $\mathrm{SAQ}^{33}$ a finding consistent with past reviews on this topic. ${ }^{12}$ The SAQ also covered the most safety culture dimensions of any of the reviewed survey, but this does not unequivocally suggest its superiority. Its 'Stress recognition' subscale (coded to 'Awareness of human limits') has been found to poorly correlate with other dimensions and hence is suggested to not adequately fit into the safety culture construct. ${ }^{70}$ Sexton and colleagues more recent survey, Safety, Communication, Operational Reliability and Engagement (SCORE), which was used in a couple of studies in this review, ${ }^{71} 72$ includes burnout and worklife balance but not stress recognition. ${ }^{73}$ This highlights that there remains no gold standard tool for measuring 
Table 4 Safety culture themes

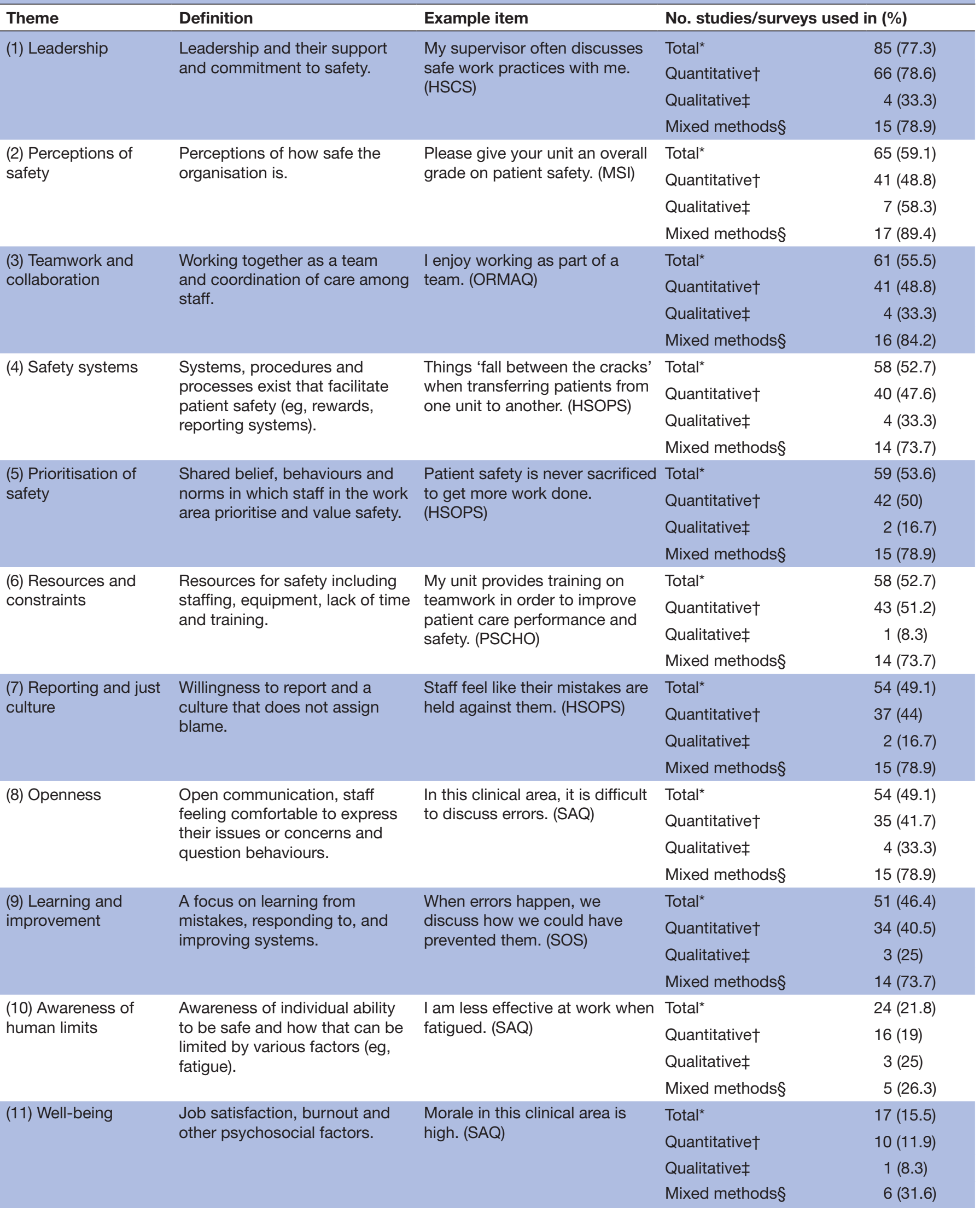


Table 4 Continued

\begin{tabular}{|c|c|c|c|c|}
\hline Theme & Definition & Example item & No. studies/surv & n (\%) \\
\hline \multirow{2}{*}{ Other } & \multirow{2}{*}{$\begin{array}{l}\text { New, emerging themes and } \\
\text { those unable to be classified } \\
\text { elsewhere. Includes: flexibility, } \\
\text { monitoring, personal values, } \\
\text { patient and family involvement. }\end{array}$} & \multirow{2}{*}{$\begin{array}{l}\text { It is important that my } \\
\text { competence be acknowledged } \\
\text { by others. (ORMAQ) }\end{array}$} & Quantitative† & $16(19)$ \\
\hline & & & Mixed methods§ & $8(42.1)$ \\
\hline
\end{tabular}

*\% of total calculated on $n=110$. Insufficient detail on five surveys and four surveys were counted in the mixed methods studies because they were single-use and developed by the authors.

$\dagger \%$ of total calculated on $n=84$.

$\ddagger \%$ of total calculated on $n=12$.

$\S \%$ of total calculated on $\mathrm{n}=19$.

HSCS, Hospital Safety Culture Survey; HSOPS, Hospital Survey on Patient Safety Culture; MSI, Modified Stanford Instrument; ORMAQ, Operating Room Management Attitudes Questionnaire; PSCHO, Patient Safety Climate in Healthcare Organisations survey; SAQ, Safety Attitude Questionnaire; SOS, Safety Organising Scale.

safety culture, limiting the capacity for comparison across studies, and the synthesis and meta-analysis of safety culture research, which is a factor that makes surveys appealing in the first instance.

\section{Qualitative and mixed methods approaches}

The present review found a relative lack of qualitative and mixed methods. Authors of studies that used qualitative or mixed methods, however, cited their value in providing deeper insights into what affects safety culture, ${ }^{61} 74$ and what the priorities should be in addressing it. For example, Sine and Northcutt ${ }^{59}$ compared findings from patient safety culture dimension survey scores (HSOPS) and the prioritisation of those dimensions by representative focus groups, which enabled understanding of how dimensions of safety culture interact with each other and the larger system of patient safety. Boussat and colleagues ${ }^{63}$ mixed method study, using the HSOPS, open response comments and in-depth interviews, found the qualitative data complemented and provided more detail to the surveys. Practically-speaking, qualitative methods were suggested to redress a common limitation of safety culture surveys in hospitals: lower than desired response

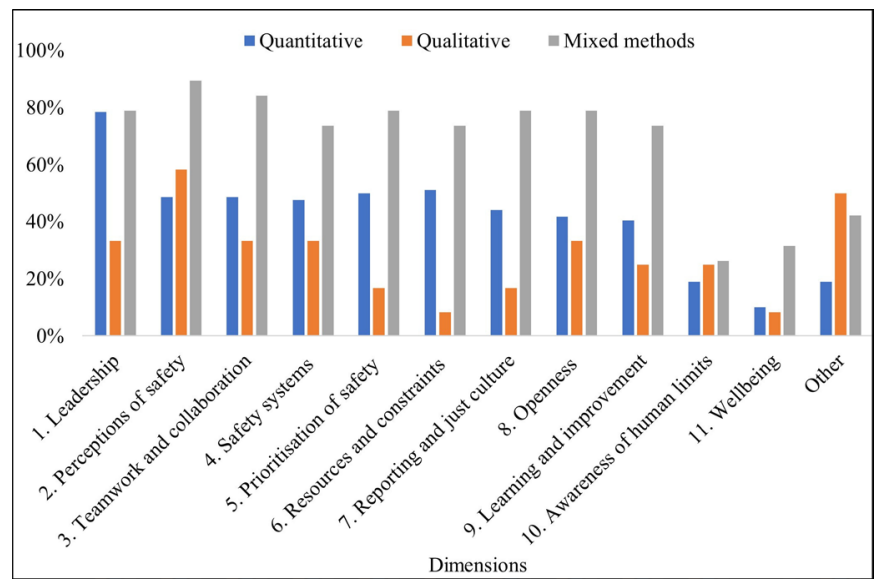

Figure 3 Proportion of methods that cover each safety culture dimension broken down by quantitative $(n=84)$, qualitative $(n=12)$ and mixed methods $(n=19)$. rates. ${ }^{74}$ Hence, evidence suggests that qualitative methods may deepen or enrich the exploration of complex issues related to safety culture, identify priority dimensions and provide insight into areas for improvement.

\section{Dimensions of safety culture}

The 11 themes related to safety culture assessment mapped to older reviews, suggesting consistency over time in the conceptualisation of core aspects of safety culture. ${ }^{9} 1219$ The areas of overlap are displayed in figure 4. Only a few dimensions of safety culture identified by Singla, et $a l^{75}$ could not be categorised elsewhere and so were included under our 'other'. Nevertheless, these categories were comparable to some of the 'other' dimensions we identified including the adequacy of junior-senior doctor supervision, ${ }^{76}$ and risk-taking behaviour. ${ }^{77}$

Similar to past reviews, ${ }^{9} 1219$ we found 'Leadership' to be the most commonly applied dimension, while personspecific themes such as 'Well-being' and 'Awareness of human limits' were less widely represented, although they were present in the popular SAQ, as well as many of the tools and methods adapted from or influenced by it. Unlike some of the previous reviews, our framework marks a distinction between the 'Perceptions of safety' (eg, 'I would feel safe being treated here as a patient' from the SAQ) and the normalised 'Prioritisation of safety' in the attitudes and behaviour of staff (eg, 'Patient safety is never sacrificed to get more work done' from the HSOPS). This allowed us to differentiate the HSOPS as providing greater coverage of the prioritisation of safety than the SAQ, a dimensions which some theorists suggest is the core feature of an organisation's safety culture. ${ }^{14}$

We found that mixed methods studies, particularly those that used comprehensive surveys (eg, SAQ, HSOPS) in conjunction with qualitative methods, covered the most safety culture themes. However, no single method or tool appeared to measure all identified dimensions of safety culture. Qualitative and mixed methods studies were more likely to assess 'other' aspects of safety culture, though, which suggests their capacity to derive unexpected, richer or more contextually relevant findings. 


Leadership and their
support for safety
-Management and
supervisors
-Management and
institutional
commitment to safety
(Management and
supervision)
-Leadership
commitment to
safety
-Top management
support \& institutional
commitment to
safety

Reporting and just
culture
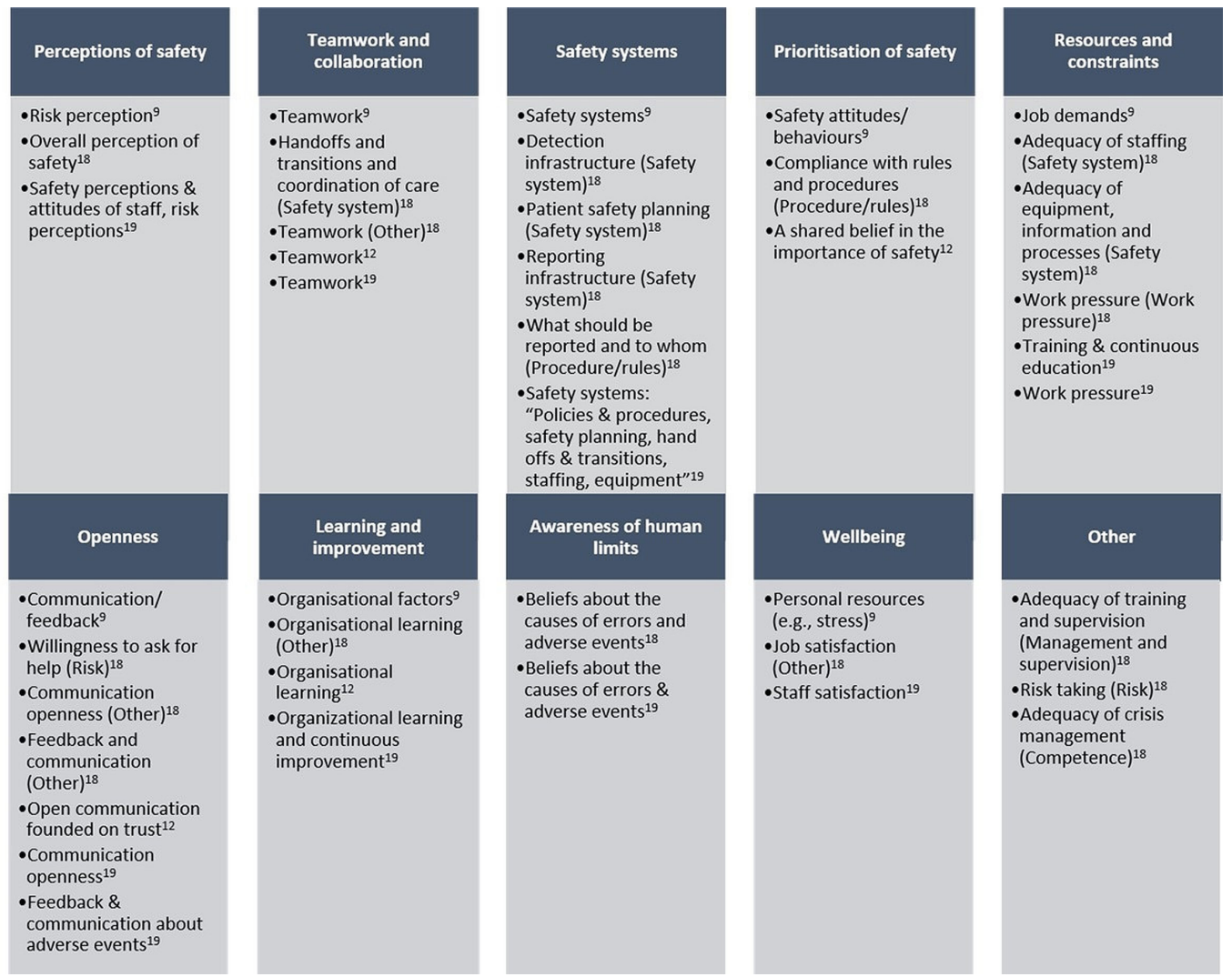

Figure 4 Overlap in dimensions of safety culture identified by this review with past reviews.

These other aspects of safety culture covered the involvement of patients in safety culture, ${ }^{416164-66}$ interpersonal dynamics $^{38}{ }^{60}$ and the context of how safety is enacted in a pressurised healthcare environment. ${ }^{45}{ }^{57}$ An emerging focus on the patient and carer and their role in safety culture was also affirmed by studies that surveyed these groups about their perceptions. ${ }^{448}$

\section{Implications for assessing safety culture for research and improvement}

Exclusively using a survey was the most common approach to assess safety culture and a comparatively large proportion of these studies had a research focus (theoretical or methodological). Studies using qualitative methods, while few in our data set, were more often exploratory or conducting a programme evaluation, suggesting the value of these methods in understanding, and improving safety culture. Nevertheless, the volume of studies using surveys for all purposes demonstrates their suitability for quality improvement through to research.

The HSOPS and SAQ were the two most widely used surveys; both provide coverage of most of the safety culture dimension. However, both have recently undergone major revisions. The HSOPS V.2.0 was released in 2019 and involved deleting, rewording and adding multiple items, with the removal of a dimension for the overall perception of patient safety. ${ }^{79}$ The SAQ has arguably been superseded by the SCORE, also developed by Sexton and colleagues, which removed one of the original dimensions and added a number of others with a greater focus on well-being. ${ }^{73}$ Given the recency of these developments, it is unclear the extent to which these revised surveys will be taken up by hospitals and researchers, though some support has emerged for making this transition. ${ }^{79}$

In general, safety culture surveys are practical, able to be used by non-experts, and time-efficient for gathering large amounts of data from one or more participant groups in a reliable and reproducible manner, which is important for researchers. ${ }^{1148} 80$ The anonymity usually involved in this form of data collection could also make them appealing for quality improvement, as they facilitate the contributions of staff who may be uncomfortable expressing their views openly. Another aspect of their attraction, surveys support comparison and benchmarking, which are often required by policymakers in healthcare. These activities are not without critique including that such measurement may lead to tunnel vision, focusing on the dimensions of performance that are included in the measurement system' (p. 570). ${ }^{81}$

Surveys have encountered similar critiques from organisational culture theorists; by reducing culture in any one organisation to a finite number of dimensions, reflected in items on a questionnaire, they may miss the 'unique profile of cultural assumptions' (p. 614). ${ }^{27}$ Our review highlights that qualitative and mixed methods approaches, on the other hand, were flexible to assessing other aspects of a hospital safety culture, and may uncover new, context specific or unexpected issues. Not only may such insights lead to future directions in research into 
safety culture, but also contribute to better understanding of culture on a micro-level and how to improve it. Furthermore, for researchers, qualitative data on safety culture can be used to augment surveys, ${ }^{63}$ particularly when one has failed to achieve a desired response rate. ${ }^{74}$ However, these methods are typically labour intensive so may not always be suited for time-poor quality improvement units within hospitals, in which case a more structured form of qualitative inquiry like the MaPSaF could be useful. ${ }^{49-51}$

Overall, findings point to the need for careful consideration and planning of the methodological approach one takes to an assessment of safety culture. Clearly using a survey is practical and feasible for capturing the perspectives of a large number of participants; however, the tool should be judiciously selected so that it covers, if not the most dimensions of safety culture, then those most important and appropriate for one's purposes, the setting and the participants. Ideally, assessment should include the use of qualitative methods in addition to surveys to enable not only greater exploration of specified dimensions, but the potential to identify other relevant aspects of safety culture.

\section{Strengths and limitations}

A strength of this study was searching four large academic databases. However, only searching academic literature leads to a high risk of publication bias. It is plausible that studies in grey literature or unpublished quality improvement projects are more inclined to contain qualitative methods than studies in academic journals where significance testing and large sample sizes are valued.

Another issue was the lack of information provided in the method of included studies to, for example, adequately identify safety culture dimensions, or even if a survey was new or an extension of an existing survey. Numerous studies of safety culture in hospitals provided inappropriate references (eg, citing a secondary source that had used the SAQ not calling the tool by its established name). Many surveys also have similar survey names and origins. Accurately capturing which surveys were used sometimes required a lengthy process of tracking through multiple sources to determine the tool being referred to. Finally, a workshop and multiple group meetings were conducted to ensure consistent coding of safety culture themes.

\section{CONCLUSION}

In their comprehensive review a decade ago, Halligan and Zecevic ${ }^{12}$ highlighted the need to move toward a common set of definitions and dimensions of safety culture in healthcare. Alas, our review has shown that there are a multitude of methods and tools available to assess safety culture in hospitals, and still no clear agreement on all of its dimensions. Certainly, some surveys and mixed method approaches appear to be more comprehensive in their coverage of safety culture themes. The review highlights the discrepancy in the large volume of studies that exclusively use surveys compared with the much smaller number employing qualitative or mixed methods. Nevertheless, it indicates the value in incorporating qualitative and mixed methods approaches to verify or extend the findings of quantitative surveys and understand some of the contextual aspects of safety culture.

Twitter Anne Hogden @annehogden, Mia Bierbaum @Mia_R_Bierbaum and Janet C Long @JanetCLong

Contributors KC, LAE, AH and MB had the original idea for the manuscript. KC and LAE led the search and data extraction. CP, AO and JCL assisted with running the searches, screening papers and data extraction. KC, LAE and CP wrote portions of the manuscript. JB provided critical feedback on the manuscript and wrote the conclusion. All authors critically revised the manuscript.

Funding Funding for a literature search, which guided the development of this review, was awarded to $\mathrm{KC}, \mathrm{LAE}, \mathrm{AH}$ and $\mathrm{MB}$ by the Australian Commission on Safety and Quality in Healthcare. JB reports funding from the National Health and Medical Research Council: NHMRC Partnership Centre in Health System Sustainability (Grant ID 9100002) and NHMRC Investigator Grant APP1176620.

Competing interests None declared.

Patient consent for publication Not required.

Provenance and peer review Not commissioned; externally peer reviewed.

Data availability statement All data relevant to the study are included in the article or uploaded as supplemental information.

Supplemental material This content has been supplied by the author(s). It has not been vetted by BMJ Publishing Group Limited (BMJ) and may not have been peer-reviewed. Any opinions or recommendations discussed are solely those of the author(s) and are not endorsed by BMJ. BMJ disclaims all liability and responsibility arising from any reliance placed on the content. Where the content includes any translated material, BMJ does not warrant the accuracy and reliability of the translations (including but not limited to local regulations, clinical guidelines, terminology, drug names and drug dosages), and is not responsible for any error and/or omissions arising from translation and adaptation or otherwise.

Open access This is an open access article distributed in accordance with the Creative Commons Attribution Non Commercial (CC BY-NC 4.0) license, which permits others to distribute, remix, adapt, build upon this work non-commercially, and license their derivative works on different terms, provided the original work is properly cited, appropriate credit is given, any changes made indicated, and the use is non-commercial. See: http://creativecommons.org/licenses/by-nc/4.0/.

\section{ORCID iDs}

Kate Churruca http://orcid.org/0000-0002-9923-3116

Louise A Ellis http://orcid.org/0000-0002-2012-1980

Chiara Pomare http://orcid.org/0000-0002-9118-7207

Anne Hogden http://orcid.org/0000-0002-4317-7960

Mia Bierbaum http://orcid.org/0000-0002-7037-4708

Janet C Long http://orcid.org/0000-0002-0553-682X

Jeffrey Braithwaite http://orcid.org/0000-0003-0296-4957

\section{REFERENCES}

1 Nieva VF, Sorra J. Safety culture assessment: a tool for improving patient safety in healthcare organizations. Qual Saf Health Care 2003;12:ii17-23.

2 Barnes SA, Compton J, Saldaña M, et al. Development and testing of Baylor Scott \& White Health's "Attitudes and Practices of Patient Safety Survey". Proc 2016;29:367-70.

3 Australian Commission on Safety and Quality in Health Care. National safety and quality health service standards guide for hospitals. Sydney, Australia: ACSQHC, 2017.

4 Ginsburg LR, Tregunno D, Norton PG. 'Not another safety culture survey': using the Canadian patient safety climate survey (CanPSCS) to measure provider perceptions of PSC across health settings. BMJ Qual Saf 2014.

5 Hogden A, Ellis LA, Churruca K. Safety culture assessment in health care: a review of the literature on safety culture assessment modes: ACSQHC, 2017. Available: https://www. safetyandquality. gov. au/ wpcontent/uploads/2017/10/Safety-Culture-Assessment-in-Health- 
Care-A-review-of-the-literature-on-safety-culture-assessmentmodes. pdf

6 Singer S, Meterko M, Baker L, et al. Workforce perceptions of hospital safety culture: development and validation of the patient safety climate in healthcare organizations survey. Health Serv Res 2007;42:1999-2021.

7 Morello RT, Lowthian JA, Barker AL, et al. Strategies for improving patient safety culture in hospitals: a systematic review. BMJ Qual Saf 2013;22:11-18.

8 Cooper MD. Navigating the safety culture construct: a review of the evidence. Psychol CFIOSH C, 2016.

9 Flin R, Burns C, Mearns K, et al. Measuring safety climate in health care. Qual Saf Health Care 2006;15:109-15.

10 Cox S, Flin R. Safety culture: Philosopher's stone or man of straw? Work \& Stress 1998;12:189-201.

11 Health Safety Commission. Organising for safety: third report of the ACSNI (Advisory Committee on the safety of nuclear installations) Study Group on human factors. Sudbury, England: HSE Books, 1993.

12 Halligan M, Zecevic A. Safety culture in healthcare: a review of concepts, dimensions, measures and progress. BMJ Qual Saf 2011;20:338-43.

13 Guldenmund FW. The nature of safety culture: a review of theory and research. Saf Sci 2000;34:215-57.

14 Zohar D. A group-level model of safety climate: testing the effect of group climate on microaccidents in manufacturing jobs. J Appl Psychol 2000;85:587.

15 Cooper Ph.D. MD. Towards a model of safety culture. Saf Sci 2000;36:111-36.

16 Reason J. Managing the risks of organizational accidents. Aldershot, UK: Ashgate Publishing Company, 1997.

17 Hofmann DA, Mark B. An investigation of the relationship between safety climate and medication errors as well as other nurse and patient outcomes. Pers Psychol 2006;59:847-69.

18 Singla AK, Kitch BT, Weissman JS. Assessing patient safety culture: a review and synthesis of the measurement tools. J Patient Saf 2006;2.

19 Alsalem G, Bowie P, Morrison J. Assessing safety climate in acute hospital settings: a systematic review of the adequacy of the psychometric properties of survey measurement tools. BMC Health Serv Res 2018:18:353.

20 Cox SJ, Cheyne AJT. Assessing safety culture in offshore environments. Saf Sci 2000;34:111-29.

21 Ek Åsa, Akselsson R. Aviation on the ground: safety culture in a ground handling company. Int J Aviat Psychol 2007;17:59-76.

22 ATM. Developing a safety culture measurement toolkit (SCMT) for European ANSPs. Eighth USA/Europe Air Traffic Management Research and Development Seminar (ATM 2009), 2009.

23 Hopkins A. Studying organisational cultures and their effects on safety. Safety Science 2006;44:875-89.

24 Schein EH. Sense and nonsense about culture and climate. In: Ashkanasy NM, Wilderom CPM, Peterson MF, eds. Handbook of Organizational Culture \& Climate. Thousand Oaks, CA: Sage, 2000.

25 Davies HT, Nutley SM, Mannion R. Organisational culture and quality of health care. Qual Health Care 2000;9:111-9.

26 Flin R. Measuring safety culture in healthcare: a case for accurate diagnosis. Saf Sci 2007;45:653-67.

27 Schein EH. So how can you assess your corporate culture. Organization Development: A Jossey-Bass Reader, 2006: 614-33.

28 Singer S, Lin S, Falwell A, et al. Relationship of safety climate and safety performance in hospitals. Health Serv Res 2009;44:399-421.

29 Jung T, Scott T, Davies HTO, et al. Instruments for exploring organizational culture: a review of the literature. Public Adm Rev 2009;69:1087-96.

30 Moher D, Liberati A, Tetzlaff J, et al. Preferred reporting items for systematic reviews and meta-analyses: the PRISMA statement. Int $J$ Surg 2010;8:336-41.

31 Fleiss $\mathrm{JL}$. Measuring nominal scale agreement among many raters. Psychol Bull 1971;76:378-82.

32 Agency for Healthcare Research and Quality. Surveys on patient safety culture Rockville, MD, US: United States Department of Health \& Human Services, 2017. Available: https://www.ahrq.gov/ professionals/quality-patient-safety/patientsafetyculture/index.htm [Accessed 26 Jun 2016]

33 Sexton JB, Helmreich RL, Neilands TB, et al. The safety attitudes questionnaire: psychometric properties, benchmarking data, and emerging research. BMC Health Serv Res 2006;6:44.

34 Schwartz ME, Welsh DE, Paull DE, et al. The effects of Crew resource management on teamwork and safety climate at Veterans health administration facilities. J Healthc Risk Manag 2018;38:17-37.
35 Schaefer $\mathrm{H}$, Helmreich $\mathrm{R}$. The operating room management attitudes questionnaire (ORMAQ). University of Texas: NASA/University of Texas FAA Technical Report Austin, 1993.

36 Singer SJ, Gaba DM, Geppert JJ, et al. The culture of safety: results of an organization-wide survey in 15 California hospitals. Qual Saf Health Care 2003;12:112-8.

37 Ginsburg L, Gilin D, Tregunno D, et al. Advancing measurement of patient safety culture. Health Serv Res 2009;44:205-24.

38 Petschonek S, Burlison J, Cross C, et al. Development of the just culture assessment tool: measuring the perceptions of health-care professionals in hospitals. J Patient Saf 2013;9:190-7.

39 Ullman AJ, Long DA, Rickard CM. Prevention of central venous catheter infections: a survey of paediatric ICU nurses' knowledge and practice. Nurse Educ Today 2014;34:202-7.

40 Durani P, Dias J, Singh HP, et al. Junior doctors and patient safety: evaluating knowledge, attitudes and perception of safety climate. BMJ Qual Saf 2013;22:65-71.

41 Wang Y, Han H, Qiu L, et al. Development of a patient safety culture scale for maternal and child health institutions in China: a crosssectional validation study. BMJ Open 2019;9:e025607.

42 Steyrer J, Latzke M, Pils K, et al. Development and validation of a patient safety culture questionnaire in acute geriatric units. Gerontology 2011;57:481-9.

43 Zhu J, Li L, Zhao H, et al. Development of a patient safety climate survey for Chinese hospitals: cross-national adaptation and psychometric evaluation. BMJ Qual Saf 2014;23:847-56.

44 Monaca C, Bestmann B, Kattein M, et al. Assessing patients' perceptions of safety culture in the hospital setting: development and initial evaluation of the patients' perceptions of safety culture scale. $J$ Patient Saf 2020;16:90-7.

45 Groves PS, Finfgeld-Connett D, Wakefield BJ. It's always something: Hospital nurses managing risk. Clin Nurs Res 2014;23:296-313.

46 Bressers G, Wallenburg I, Stalmeijer R, et al. Patient safety in medical residency training: balancing bravery and checklists. Health 2020;13 63459319899444:1363459319899444.

47 Abdi Z, Delgoshaei B, Ravaghi H, et al. The culture of patient safety in an Iranian intensive care unit. J Nurs Manag 2015;23:333-45.

48 Listyowardojo TA, Yan X, Leyshon S, et al. A safety culture assessment by mixed methods at a public maternity and infant hospital in China. J Multidiscip Healthc 2017;10:253.

49 Simons PAM, Houben R, Vlayen A, et al. Does lean management improve patient safety culture? an extensive evaluation of safety culture in a radiotherapy Institute. Eur J Oncol Nurs 2015;19:29-37.

50 Lachman P, Linkson L, Evans T, et al. Developing person-centred analysis of harm in a paediatric Hospital: a quality improvement report. BMJ Qual Saf 2015;24:337-44.

51 Simsekler MCE. The link between healthcare risk identification and patient safety culture. Int J Health Care Qual Assur 2019;32:574-87.

52 Öhrn A, Rutberg H, Nilsen P. Patient safety dialogue: evaluation of an intervention aimed at achieving an improved patient safety culture. $J$ Patient Saf 2011;7:185-92.

53 Parker D. Managing risk in healthcare: understanding your safety culture using the Manchester patient safety framework (MaPSaF). $J$ Nurs Manag 2009;17:218-22.

54 Law MP, Zimmerman R, Baker GR, et al. Assessment of safety culture maturity in a hospital setting. Healthc Q 2010;13 Spec No:110-5.

55 Gimenes FRE, Torrieri MCGR, Gabriel CS, et al. Applying an ecological restoration approach to study patient safety culture in an intensive care unit. J Clin Nurs 2016;25:1073-85.

56 Elder NC, Brungs SM, Nagy M, et al. Intensive care unit nurses perceptions of safety after a highly specific safety intervention. Qual Saf Health Care 2008;17:25-30.

57 Gillespie BM, Gwinner K, Chaboyer W, et al. Team communications in surgery - creating a culture of safety. $J$ Interprof Care 2013;27:387-93.

58 Livorsi D, Knobloch MJ, Blue LA, et al. A rapid assessment of barriers and facilitators to safety culture in an intensive care unit. Int Nurs Rev 2016;63:372-6.

59 Sine DM, Northcutt N. Interactive qualitative assessment of patient safety culture survey scores. J Patient Saf 2008;4:78-83.

60 Kenneth Milne J, Bendaly N, Bendaly L, Milne JK, Bendaly L, et al. A measurement tool to assess culture change regarding patient safety in hospital obstetrical units. J Obstet Gynaecol Can 2010;32:590-7.

61 Wami SD, Demssie AF, Wassie MM, et al. Patient safety culture and associated factors: a quantitative and qualitative study of healthcare workers' view in Jimma zone hospitals, Southwest Ethiopia. BMC Health Serv Res 2016:16:495.

62 Bognár A, Barach P, Johnson JK, et al. Errors and the burden of errors: attitudes, perceptions, and the culture of safety in pediatric cardiac surgical teams. Ann Thorac Surg 2008;85:1374-81. 
63 Boussat B, Kamalanavin K, François P. The contribution of open comments to understanding the results from the hospital survey on patient safety culture (HSOPS): a qualitative study. PLoS One 2018;13:e0196089.

64 Abu-El-Noor NI, Abu-El-Noor MK, Abuowda YZ, et al. Patient safety culture among nurses working in Palestinian governmental Hospital: a pathway to a new policy. BMC Health Serv Res 2019;19:550.

65 Kagan I, Porat N, Barnoy S. The quality and safety culture in general hospitals: patients', physicians' and nurses' evaluation of its effect on patient satisfaction. Int J Qual Health Care 2019;31:261-8.

66 Matsubara S, Hagihara A, Nobutomo K. Development of a patient safety climate scale in Japan. Int J Qual Health Care 2008;20:211-20.

67 Wailling J, Robinson B, Coombs M, Surveillance CM. Surveillance, anticipation and firefighting: perspectives of patient safety from a new Zealand case study. J Nurs Manag 2019;27:939-45.

68 Ausserhofer D, Schubert M, Engberg S, et al. Nurse-reported patient safety climate in Swiss hospitals: a descriptive-explorative substudy of the Swiss RN4CAST study. Swiss Med Wkly 2012;142:w13501.

69 Kyratsis Y, Ahmad R, Iwami M, et al. A multilevel neo-institutional analysis of infection prevention and control in English hospitals: coerced safety culture change? Sociol Health IIIn 2019;41:1138-58.

70 Taylor JA, Pandian R. A dissonant scale: stress recognition in the SAQ. BMC Res Notes 2013;6:302.

71 Sexton JB, Adair KC, Leonard MW, et al. Providing feedback following leadership WalkRounds is associated with better patient safety culture, higher employee engagement and lower burnout. BMJ Qual Saf 2018;27:261-70.

72 Lefebvre G, Honey L, Hines K, et al. Implementing obstetrics quality improvement, driven by medico-legal risk, is associated with improved workplace culture. J Obstet Gynaecol Can 2020;42:38-47.

73 Sexton JB, Frankel A, Leonard M. SCORE: assessment of your work setting. Durham, NC: Duke University, 2019.
74 Allen S, Chiarella M, Homer CSE. Lessons learned from measuring safety culture: an Australian case study. Midwifery 2010;26:497-503.

75 Singla AK, Kitch BT, Weissman JS. Assessing patient safety culture: a review and synthesis of the measurement tools. J Patient Saf 2006;2:105-15

76 Johnston MJ, Arora S, King D, et al. Improving the quality of wardbased surgical care with a human factors intervention bundle. Ann Surg 2018;267:73-80.

77 Kirkegaard ML, Kines P, Nielsen HB, et al. Occupational safety across jobs and shifts in emergency departments in Denmark. Saf Sci 2018;103:70-5.

78 Cox ED, Carayon P, Hansen KW, et al. Parent perceptions of children's Hospital safety climate. BMJ Qual Saf 2013;22:664-71.

79 Sorra J, Famolaro T, Yount N. Transitioning to the SOPSTM hospital survey version 2.0: what's different and what to expect, part I: main report. AHRQ Publication No 19-0076-1-EF. 17. Rockville, MS: Westat, 2019.

80 Roney L, Sumpio C, Beauvais AM, et al. Describing clinical faculty experiences with patient safety and quality care in acute care settings: a mixed methods study. Nurse Educ Today 2017;49:45-50.

81 Mannion R, Braithwaite J. Unintended consequences of performance measurement in healthcare: 20 salutary lessons from the English National health service. Intern Med J 2012;42:569-74.

82 Thomas EJ, Sexton JB, Neilands TB, et al. The effect of executive walk rounds on nurse safety climate attitudes: a randomized trial of clinical units[ISRCTN85147255] [corrected]. BMC Health Serv Res 2005;5:28.

83 Gershon RR, Karkashian CD, Grosch JW, et al. Hospital safety climate and its relationship with safe work practices and workplace exposure incidents. Am J Infect Control 2000;28:211-21. 